Article

\title{
High-Cholesterol Diet Decreases the Level of Phosphatidylinositol 4,5-Bisphosphate by Enhancing the Expression of Phospholipase C (PLC $\beta 1$ ) in Rat Brain
}

\author{
Yoon Sun Chun and Sungkwon Chung * \\ Department of Physiology, Sungkyunkwan University School of Medicine, Suwon, Gyeonggi-do 16419, Korea; \\ ysun129@skku.edu \\ * Correspondence: schung@skku.edu; Tel.: +82-31-299-6103
}

Received: 17 December 2019; Accepted: 8 February 2020; Published: 10 February 2020

check for updates

\begin{abstract}
Cholesterol is a critical component of eukaryotic membranes, where it contributes to regulating transmembrane signaling, cell-cell interaction, and ion transport. Dysregulation of cholesterol levels in the brain may induce neurodegenerative diseases, such as Alzheimer's disease, Parkinson disease, and Huntington disease. We previously reported that augmenting membrane cholesterol level regulates ion channels by decreasing the level of phosphatidylinositol 4,5-bisphosphate $\left(\mathrm{PIP}_{2}\right)$, which is closely related to $\beta$-amyloid $(\mathrm{A} \beta)$ production. In addition, cholesterol enrichment decreased $\mathrm{PIP}_{2}$ levels by increasing the expression of the $\beta 1$ isoform of phospholipase $C$ (PLC) in cultured cells. In this study, we examined the effect of a high-cholesterol diet on phospholipase $\mathrm{C}$ (PLC $\beta 1$ ) expression and $\mathrm{PIP}_{2}$ levels in rat brain. $\mathrm{PIP}_{2}$ levels were decreased in the cerebral cortex in rats on a high-cholesterol diet. Levels of PLC $\beta 1$ expression correlated with $\mathrm{PIP}_{2}$ levels. However, cholesterol and $\mathrm{PIP}_{2}$ levels were not correlated, suggesting that $\mathrm{PIP}_{2}$ level is regulated by cholesterol via PLC $\beta 1$ expression in the brain. Thus, there exists cross talk between cholesterol and PIP $_{2}$ that could contribute to the pathogenesis of neurodegenerative diseases.
\end{abstract}

Keywords: phosphatidylinositol 4,5-bisphosphate; phospholipase C; cholesterol; high-cholesterol diet

\section{Introduction}

Lipid metabolism including cholesterol, oxysterols, fatty acids, and phospholipids is involved in numerous neurodegenerative diseases including Alzheimer's disease [1,2]. Cholesterol is a key component of plasma membrane bilayers, where it affects structural and physical functions including fluidity, curvature, and stiffness. It also regulates the functions of membrane proteins and is involved in transmembrane signaling processes, membrane trafficking, endocytosis, and ion transport $[3,4]$. Cholesterol also participates in the biosynthesis of bile acids and steroid hormones in the plasma membrane, which in turn play important functional and biological roles as signal transducers [5]. Cholesterol is particularly enriched in the brain, and the central nervous system contains $23 \%$ of all cholesterol in the whole human body. Cholesterol in neurons and astrocytes controls synaptic transmission [6]. Thus, changes in cholesterol levels and homeostasis have been associated with brain diseases and neurodegenerative disorders such as Alzheimer's disease (AD), Parkinson's disease (PD), and Huntington's disease [7].

Phosphatidylinositol 4,5-bisphosphate ( $\mathrm{PIP}_{2}$ ) plays a pivotal role in cell membranes, regulating biological functions including signal transduction, membrane trafficking, transporter functions, and ion channels [8,9]. Phospholipase C (PLC), which is grouped into four major families $(\beta, \gamma, \delta$, and $\varepsilon)$, hydrolyzes $\mathrm{PIP}_{2}$ to produce inositol 1,4,5-trisphosphate and diacylglycerol [10]. These products 
induce calcium release from intracellular stores and activate phosphorylation of cAMP response element-binding protein and neuronal gene expression in the brain [11,12]. Decrease of $\mathrm{PIP}_{2}$ in the cell membrane results in impaired long-term potentiation and reduced cognition [13]. Levels of $\mathrm{PIP}_{2}$ are closely related to the production of $\beta$-amyloid peptide (A $\beta)$, a culprit in AD [14]. Many ion channels are regulated by $\mathrm{PIP}_{2}$, and the hydrolysis of $\mathrm{PIP}_{2}$ by phospholipase $\mathrm{C}$ has been shown to reduce their activities [8]. We demonstrated that augmenting membrane cholesterol levels regulated ion channels by decreasing $\mathrm{PIP}_{2}$ [15], suggesting that a close relationship between plasma membrane-enriched lipids, cholesterol, and $\mathrm{PIP}_{2}$. The human ether-a-go-go related gene (HERG) $\mathrm{K}^{+}$channel, which is known to be modulated by $\mathrm{PIP}_{2}$, is inhibited by cholesterol enrichment via increased phospholipase $\mathrm{C}$ (PLC $\beta 1$ ) expression [16]. Consistent with this, we showed that increasing cholesterol levels in cultured cells increased PLC $\beta 1$ and PLC $\beta 3$ expression levels among PLC isoforms ( $\beta 1, \beta 2, \beta 3, \beta 4, \gamma 1$, and $\gamma 2)$ and increased PLC $\beta 1$ expression induced the decrease of PIP 2 levels [17]. These results suggest that there may exist cross talk among two plasma membrane-enriched lipids, cholesterol and $\mathrm{PIP}_{2}$, via expression of PLC $\beta 1$. However, these results obtained from cultured cells are not confirmed in the brain yet.

In this study, we tested whether cholesterol enrichment affected PLC $\beta 1$ expression and PIP 2 level in brain. We found that $\mathrm{PIP}_{2}$ levels decreased significantly in the cerebral cortices of rats on a high-cholesterol diet, repeating our previous in vitro result [15]. The high-cholesterol diet slightly increased expression of PLC $\beta 1$ but not that of PLC $\beta 3$. Levels of PLC $\beta 1$ expression correlated with those of $\mathrm{PIP}_{2}$, whereas levels of cholesterol and $\mathrm{PIP}_{2}$ did not. These results could suggest that $\mathrm{PIP}_{2}$ levels are regulated by cholesterol via PLC $\beta 1$ expression in the brain.

\section{Results}

\subsection{PIP 2 Levels Were Down-Regulated in Rats on a High-Cholesterol Diet}

We previously found that enriching membrane cholesterol decreased $\mathrm{PIP}_{2}$ in cultured cells $[14,16]$. In order to test whether cholesterol augmentation in the brain affects levels of $\mathrm{PIP}_{2}$ in vivo, 13-week-old Sprague Dawley (SD) rats were fed with either normal or high-cholesterol diets for 6 weeks [18-21]. We observed that the body weight was not altered in high-cholesterol diet rats compared to normal diet rats (data not shown). First, we tested the levels of free cholesterol in the cerebral cortex. For this purpose, we obtained the membrane fractions from the cerebral cortices and measured the levels of free membrane cholesterol using assay kits. As shown in Figure 1A, the free cholesterol level was $390 \pm$ $29 \mu \mathrm{g} / \mathrm{mL}(n=10)$ in the rats on the normal diet, whereas it increased by $15 \%$ to $450 \pm 44 \mu \mathrm{g} / \mathrm{mL}(n=10)$ in the rats on the high-cholesterol diet. Cholesterol levels was increased by $15.4 \%$ by high-cholesterol diet. However, the difference between the two groups was not statistically significant $(p=0.24)$. This was likely owing to the varying cholesterol levels within each group as shown by scattered data in Figure 1A. Alternatively, the non-significant difference could have been because of the existence of different pools of cholesterol in the central nervous system. We next analyzed the PIP $\mathrm{P}_{2}$ levels in the cerebral cortex membranes using assay kits. As shown in Figure 1B, PIP 2 levels were $5.81 \pm 0.34 \mathrm{pM}$ $(n=10)$ in the rats on the normal diet, but they significantly decreased by $12.9 \%$ to $5.06 \pm 0.26 \mathrm{pM}$ $(n=10)$ in the rats on the high-cholesterol diet. These data indicate that $\mathrm{PIP}_{2}$ was down-regulated by cholesterol augmentation in vivo. 
A)

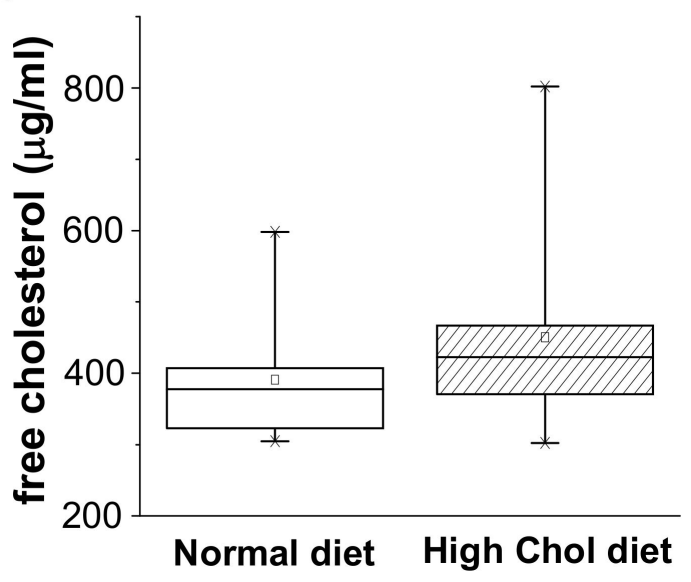

B)

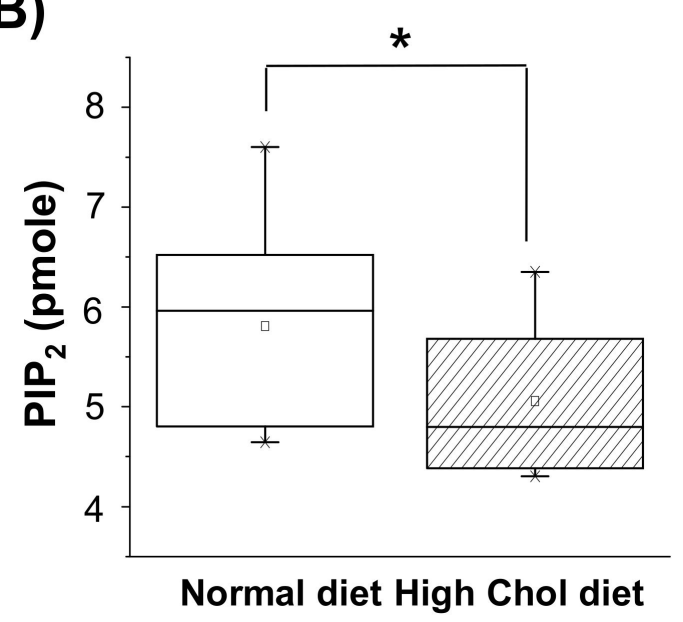

Figure 1. High-cholesterol diet decreased phosphatidylinositol 4,5-bisphosphate ( $\mathrm{PIP}_{2}$ ) levels in the rat cerebral cortex. Starting at 13 weeks of age, 10 male rats were placed on a high-cholesterol diet and 10 male rats were placed on a normal diet for 6 weeks as described in Materials and Methods. Cerebral cortex was removed and membrane and cytosol fractions were obtained. (A) The levels of free cholesterol in the membrane fractions were measured by cholesterol assay kit. Box plots show average cholesterol level in normal diet (open bar) or high-cholesterol diet (hatched bar) groups. The horizontal black lines represent the median of each distribution and the squares indicate means $(n=10)$. (B) $\mathrm{PIP}_{2}$ levels in the membrane fractions were measured by using $\mathrm{PIP}_{2}$ ELISA kit. The levels of PIP 2 were decreased by a high-cholesterol $\operatorname{diet}(n=10) .{ }^{*} p<0.05$.

\subsection{PLC $\beta 1$ Expression Increased in Rats on a High-Cholesterol Diet}

The hydrolysis of $\mathrm{PIP}_{2}$ mediated by PLC is the major catabolic pathway for $\mathrm{PIP}_{2}$ [10]. Because we found that increased cholesterol levels led to increased PLC $\beta 1$ expression in the cultured cells [17], we examined whether high-cholesterol diet in rats affected expressions of PLC $\beta 1$ and PLC $\beta 3$. Levels of PLC expressions were measured from the cytosol and membrane fractions of the cerebral cortices using Western blot analysis. A typical Western blot for PLC $\beta 1$ and PLC $\beta 3$ is shown in Figure 2A. Full images of Western blot are shown in Supplementary Figures S1 and S2. All Western blot bands for PLC $\beta 1$ in membrane and cytosol fractions are shown in Supplementary Figure S3. We confirmed equal protein loading by $\beta$-tubulin levels, and the relative band densities of PLC $\beta 1$ and PLC $\beta 3$ compared with $\beta$-tubulin are shown in Figure 2B, C $(n=10)$. PLC $\beta 1$ expression slightly increased in membrane fractions from rats on the high-cholesterol diet although the effect was not statistically significant (Figure 2B; $p=0.512$ ). The high-cholesterol diet did not affect the PLC $\beta 1$ expression in the cytosol fraction, and the PLC $\beta 3$ expression in both the cytosol and membrane fractions showed no differences between the two groups (Figure 2C).

\subsection{PLC $\beta 1$ Expression Directly Correlated with PIP 2 Levels}

We compared the PLC $\beta 1$ and PLC $\beta 3$ expression along with PIP 2 levels from individual rats. We hypothesized that if PLC expression directly affected $\mathrm{PIP}_{2}$, these two would correlate. As shown in Figure 3A, we compared PLC $\beta 1$ expression (shown as relative to tubulin expression) with PIP 2 levels. There was a moderate correlation between them (RSQ, 0.297) from rat brains on the normal diet (open symbols, and a thin line). Interestingly, the PLC $\beta 1$ expression and $\mathrm{PIP}_{2}$ levels were more tightly correlated in the rats on the high-cholesterol diet (closed symbols and a thick line; RSQ, 0.345). These results suggested that even in the normal diet rats, $\mathrm{PIP}_{2}$ level in the brain correlated closely with PLC $\beta 1$ expression and that when cholesterol levels increased in high-cholesterol diet rats, the correlation and significance increased further. In the case of PLC $\beta 3$, however, there was no correlation between its expression levels and $\mathrm{PIP}_{2}$ levels in either the normal (open symbols; Figure 3B) or the 
high-cholesterol (closed symbols; Figure 3B) diet rats. Consistent with this, we previously showed that increasing cholesterol levels in cultured cells decreased PIP 2 levels by increasing PLC $\beta 1$ expression, but not by increasing PLC $\beta 3$ expression [17].

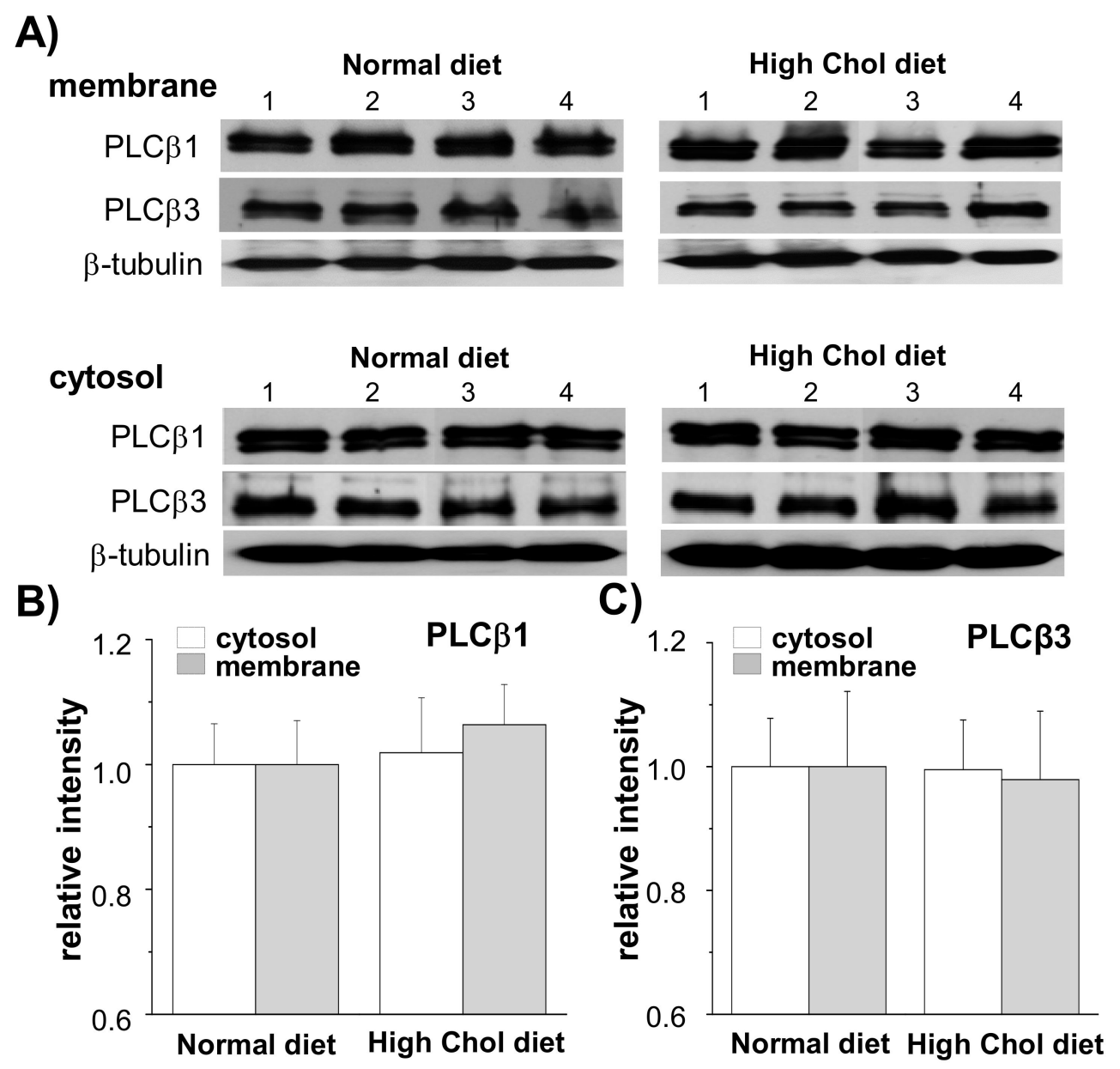

Figure 2. High-cholesterol diet slightly increased phospholipase C (PLC $\beta 1$ ) expression levels in the rat cerebral cortex. The expression levels of PLC $\beta 1$ and PLC $\beta 3$ were measured from the cytosol and membrane fractions of cerebral cortex using Western blot analysis. Representative Western blots are shown for PLC $\beta 1$ and PLC $\beta 3$. $\beta$-tubulin was used to confirm the amount of proteins loaded. (A) Expression levels of PLC $\beta 1$ and PLC $\beta 3$ were compared. (B,C) Bars indicate the levels of PLC $\beta 1$ (B) and PLC $\beta 3(\mathbf{C})$ obtained from densitometric analysis of Western bands in $(\mathbf{A})(n=10)$.

We next compared $\mathrm{PIP}_{2}$ levels along with cholesterol levels. As shown in Figure 3C, there was no correlation between $\mathrm{PIP}_{2}$ and cholesterol levels in either the normal (open symbols) or the high-cholesterol (closed symbols) diet rats, indicating that cholesterol level may not directly affect $\mathrm{PIP}_{2}$. Together, these results may indicate that the increased cholesterol level in the brain slightly increased PLC $\beta 1$ expression, reducing levels of $\mathrm{PIP}_{2}$. The effect of the high-cholesterol diet on the expression levels was specific for PLC $\beta 1$ given that we found no correlation between levels of PLC $\beta 3$ and PIP 2 . 

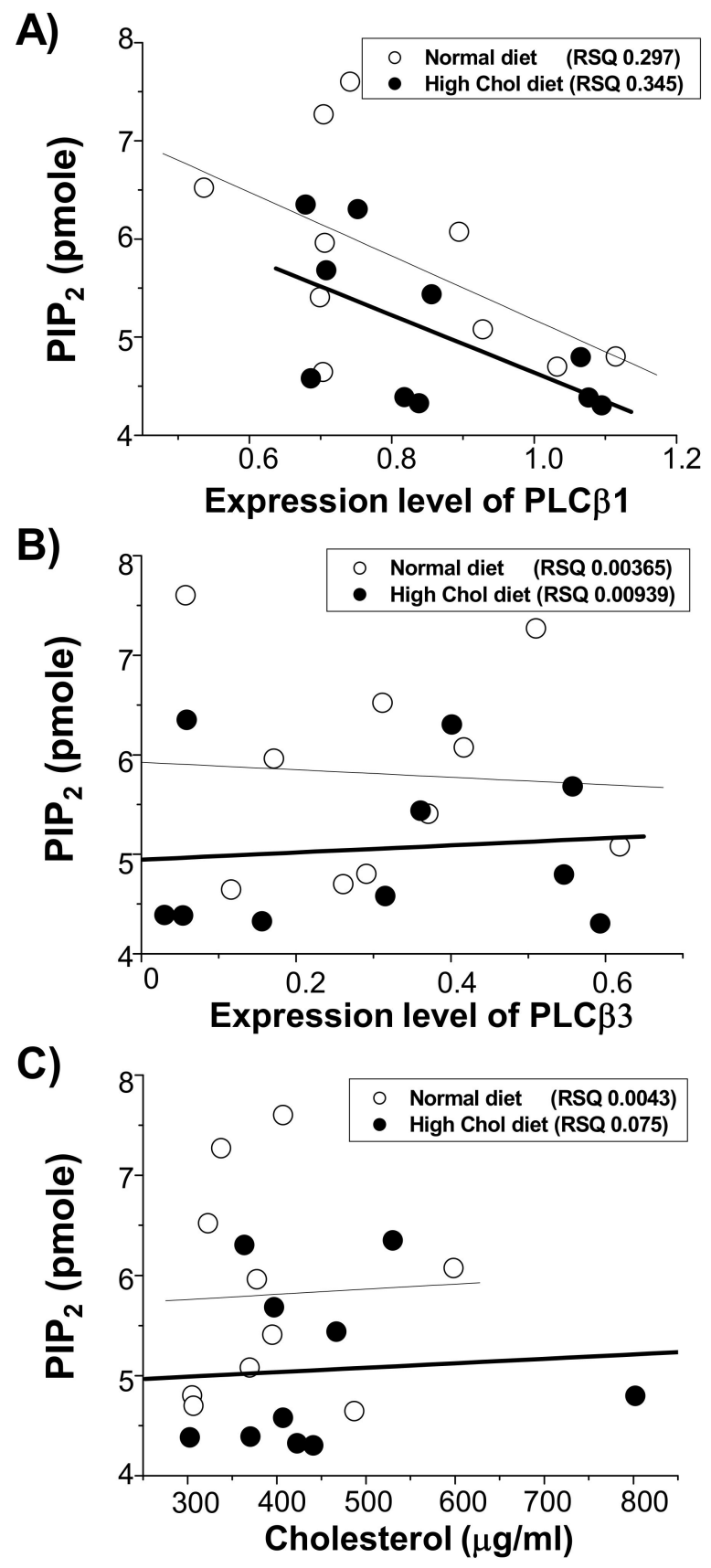

Figure 3. $\mathrm{PIP}_{2}$ levels correlated with the PLC $\beta 1$ expression levels in the rat cerebral cortex. $\mathrm{PIP}_{2}$ levels, PLC $\beta 1$ expression levels, PLC $\beta 3$ expression levels, and cholesterol levels from Figures 1 and 2 were re-plotted. Linear regressions were performed to obtain RSQ values from rats on normal diet (open symbols and a thin line), and from rats on a high-cholesterol diet (closed symbols and thick line). (A) PIP 2 levels correlated with the PLC $\beta 1$ expression levels. (B) There was no correlation between $\mathrm{PIP}_{2}$ levels and PLC $\beta 3$ expression levels. (C) There was no correlation between $\mathrm{PIP}_{2}$ levels and cholesterol levels.

\section{Discussion}

In this study, we demonstrated that a high-cholesterol diet significantly decreased $\mathrm{PIP}_{2}$ levels and slightly increased PLC $\beta 1$ expression. The correlation between PIP 2 level and PLC $\beta 1$ expression further increased in high-cholesterol diet rats. In the high-cholesterol diet rats, cholesterol increased by $15 \%$ compared with the rats on normal diet, although the difference was not statistically significant, likely because of the varying cholesterol levels in each group. These varying levels may also explain 
why there was no significant effect of the high-cholesterol diet on the PLC $\beta 1$ expression. Importantly, however, there existed a correlation between the expression and $\mathrm{PIP}_{2}$ levels even in the normal diet rats, and the correlation increased further in the high-cholesterol diet rats, indicating that the increased PLC $\beta 1$ expression by the high-cholesterol diet might have resulted in $\mathrm{PIP}_{2}$ hydrolysis. These results suggest that there exist relationships among cholesterol, PIP $P_{2}$, and PLC $\beta 1$ in the brain. We tested the effect of dietary cholesterol on levels of $\mathrm{PIP}_{2}$ and PLC $\beta 1$ in healthy young male rat. However, it was shown that different physiological conditions such as gender and age could affect a dysregulation in brain cholesterol metabolism [22,23]. In addition, cholesterol concentration in serum significantly differed in male and female rats fed the cholesterol-containing diet [24]. Thus, further experiments will be needed to compare the effect of a high-cholesterol diet on PLC $\beta 1$ expression and PIP 2 levels by gender and age.

$\mathrm{PIP}_{2}$ is a minor lipid component in the plasma membrane, localized to the cytoplasmic leaflet of the phospholipid bilayer [25]. It plays important roles in the attachment of the cytoskeleton to the plasma membrane, endocytosis, membrane trafficking, and enzyme activation [9]. A previous report suggests that there exist different pools of $\mathrm{PIP}_{2}$ in the cell membrane to play its multiple roles [26]. $\mathrm{PIP}_{2}$ levels are determined through their production by phosphoinositide kinases and through their breakdown by phosphatases and phosphoinositide-specific PLC. Our results showed that $\mathrm{PIP}_{2}$ was closely related to PLC $\beta 1$ expression but there was no correlation with PLC $\beta 3$ expression, and these results are consistent with our previous report on cultured cells [17]. Taken together, we concluded that cholesterol enrichment specifically increased the expression of PLC $\beta 1$, resulting in the down-regulation of $\mathrm{PIP}_{2}$. Lipid raft may serve as a platform for the specific regulation of PLC $\beta 1$ expression by cholesterol enrichment, since it is known as a microdomain enriched with cholesterol $[27,28]$. PIP 2 is shown to localize in lipid rafts [29-31]. Interestingly, PLC $\beta 1$ is also localized in lipid raft microdomains, when prepared from the synaptic plasma membrane fraction of rat brains [32]. However, further studies will be needed to clarify how cholesterol regulates PLC $\beta 1$ PLC $\beta 1$ expression.

Cholesterol is essential for structural and physiological functions of neurons [4]. It has been suggested that changes in cholesterol homeostasis induce synaptic degeneration and the disruption of brain functions, contributing to neurodegenerative diseases [33]. Some studies showed that a high plasma cholesterol level increases the risk of developing PD [34], and the decrease of plasma cholesterol by statin might attenuate the deposition of $\alpha$-synuclein in the brain [35]. The association of cholesterol with $\mathrm{AD}$ is one of the most studied topics [36]. Cholesterol levels are closely connected to the production of $A \beta$ [37-39]. Also, cholesterol accumulates in senile plaques of AD patients and in transgenic $\mathrm{APP}(\mathrm{SW})$ mice [40]. Hypercholesterolemia has been shown to increase A $\beta$ deposition and amyloid plaque formation in a transgenic mouse model [21]. Consistently, cholesterol synthesis inhibitors, statins, decrease $A \beta$ production [41]. Since levels of $\mathrm{PIP}_{2}$ are closely related to the production of $\mathrm{A} \beta$ [14], $\mathrm{PIP}_{2}$ may serve as the important molecule that links cholesterol to the pathogenesis of neurodegenerative diseases such as $\mathrm{AD}$.

\section{Materials and Methods}

\subsection{High-Cholesterol Diet}

Starting at 13 weeks of age, 10 male SD rats were placed on a high-cholesterol diet containing $5 \%$ cholesterol, $10 \%$ fat, and $2 \%$ sodium cholate for 6 weeks. A total of 10 animals were also placed on a normal diet containing $0.005 \%$ cholesterol and $10 \%$ fat for 6 weeks. The cerebral cortices were removed and immediately frozen and stored at $-80^{\circ} \mathrm{C}$. All experiments on rats were carried out in accordance with the approved animal care and use guidelines of the Laboratory Animal Research Center in Sungkyunkwan University School of Medicine and all experimental protocols were approved by the Laboratory Animal Research Center in Sungkyunkwan University School of Medicine (\#skkumed10-05, 10 January 2010). 


\subsection{Protein Extraction}

The cerebral cortices were homogenized in Tris-buffered saline solution $(20 \mathrm{mM}$ Tris, $137 \mathrm{mM} \mathrm{NaCl}$, $\mathrm{pH}$ 7.4) containing a protease inhibitor cocktail, and the extraction ratio (brain tissue: Tris-buffered saline) was 1:10 (w/v). Homogenate samples were sonicated for $1 \mathrm{~min}$ on ice and centrifuged at $1000 \times g$ for $10 \mathrm{~min}$ at $4{ }^{\circ} \mathrm{C}$ to remove nuclei and debris. Supernatants were separated into membranes (pellet) and cytosols (supernatant) by centrifugation at $100,000 \times \mathrm{g}$ for $1 \mathrm{~h}$ at $4{ }^{\circ} \mathrm{C}$. The pellet was lysed with Ripa buffer (25 mM Tris, $5 \mathrm{mM}$ EDTA, $137 \mathrm{mM} \mathrm{NaCl}, 1 \%$ Triton X-100, $1 \%$ sodium deoxycholate, $0.1 \%$ SDS with a protease inhibitor cocktail, $\mathrm{pH}$ 7.4). The protein content was measured by Bradford assay (Bio-Rad Laboratories, Hercules, CA, USA).

\subsection{Cholesterol Assay}

We measured cholesterol using the Amplex Red cholesterol assay kit (Thermo Fisher Scientific, Halethorpe, CA, USA). Homogenate samples were centrifuged at $1000 \times g$ for $10 \mathrm{~min}$ to remove nuclei and cell debris. Membranes were pelleted from the supernatants by centrifugation for $1 \mathrm{~h}$ at $100,000 \times g$ at $4{ }^{\circ} \mathrm{C}$ and analyzed according to the supplier's instructions.

\subsection{Western Blot Analysis}

We resolved protein from each sample on SDS-PAGE and transferred the resolved protein to nitrocellulose membrane. Membranes were blocked with $5 \%$ nonfat milk powder in Tris-buffered saline/Tween 20 (TBST) for $1 \mathrm{~h}$ at room temperature, followed by incubation with anti-PLC $\beta 1$ (Santa Cruz Biotechnologies, Dallas, TX, USA), anti-PLC $\beta 3$ (Santa Cruz Biotechnologies), and anti- $\beta$-tubulin (Sigma-Aldrich, St. Louis, MO, USA) antibodies for overnight at $4{ }^{\circ} \mathrm{C}$; the dilutions were 1:500 for the PLC isozymes and 1:4000 for $\beta$-tubulin. After being washed with TBST, the membranes were incubated with horseradish peroxidase-conjugated goat anti-rabbit IgG (Invitrogen, Waltham, MA, USA) for $1 \mathrm{~h}$ at room temperature. We visualized the peroxidase activity with enhanced chemiluminescence and quantified the detected signals using the Fujifilm LAS-3000 system with Multi Gauge software (Tokyo, Japan).

\subsection{PIP 2 Assay}

We measured the amount of $\mathrm{PIP}_{2}$ extracted from the membrane fractions of the homogenate using a PIP 2 Mass ELISA kit (Echelon Biosciences Inc., Salt Lake City, CA, USA). We extracted the $\mathrm{PIP}_{2}$ from the normal and high-cholesterol diet groups according to the supplier's instructions. We also estimated the cellular $\mathrm{PIP}_{2}$ quantities by comparing the values from the standard curve, which showed linear relationships at concentrations ranging from 0.5 to $1000 \mathrm{pM}$.

\subsection{Statistical Analysis}

Data were expressed as mean \pm SEM. We performed statistical comparisons between controls and treated experimental groups using one-way ANOVA and considered $p<0.05$ statistically significant. Box plot graphs was used to show the distribution of the observed data variation, which displayed as minimum to maximum value together with distribution around the median and 25th and 75th percentile as edges.

Supplementary Materials: Supplementary materials can be found at http://www.mdpi.com/1422-0067/21/3/1161/ s1.

Author Contributions: S.C. and Y.S.C. designed the study and wrote the manuscript. Y.S.C. performed all experiments. All authors have read and agreed to the published version of the manuscript.

Funding: This work was supported by the Basic Science Research Program through the National Research Foundation of Korea funded by the Ministry of Education, Science and Technology (2016R1D1A1A099) to S.C.

Conflicts of Interest: The authors declare no conflict of interest. 


\section{References}

1. Zarroukeg, A.; Debbabi, M.; Bezine, M.; Karym, E.M.; Badreddine, A.; Rouaud, O.; Moreau, T.; Cherkaoui-Malki, M.; El Ayeb, M.; Nasser, B.; et al. Lipid Biomarkers in Alzheimer's Disease. Curr. Alzheimer Res. 2018, 15, 303-312. [CrossRef] [PubMed]

2. Mesa-Herrera, F.; Taoro-González, L.; Valdés-Baizabal, C.; Diaz, M.; Marín, R. Lipid and Lipid Raft Alteration in Aging and Neurodegenerative Diseases: A Window for the Development of New Biomarkers. Int. J. Mol. Sci. 2019, 20, 3810. [CrossRef] [PubMed]

3. Cerqueira, N.M.; Oliveira, E.F.; Gesto, D.S.; Santos-Martins, D.; Moreira, C.; Moorthy, H.N.; Ramos, M.J.; Fernandes, P.A. Cholesterol biosynthesis: A mechanistic overview. Biochemistry 2016, 55, 5483-5506. [CrossRef] [PubMed]

4. Pfrieger, F.W. Cholesterol homeostasis and function in neurons of the central nervous system. Cell. Mol. Life Sci. 2003, 60, 1158-1171. [CrossRef]

5. Van der Kant, R.; Zondervan, I.; Janssen, L.; Neefjes, J. Cholesterol-binding molecules MLN64 and ORP1L mark distinct late endosomes with transporters ABCA3 and NPC1. J. Lipid Res. 2013, 54, 2153-2165. [CrossRef] [PubMed]

6. Dietschy, J.M.; Turley, S.D. Thematic review series: Brain Lipids. Cholesterol metabolism in the central nervous system during early development and in the mature animal. Lipid Res. 2004, 45, 1375-1397. [CrossRef]

7. Arenas, F.; Garcia-Ruiz, C.; Fernandez-Checa, J.C. Intracellular Cholesterol Trafficking and Impact in Neurodegeneration. Front. Mol. Neurosci. 2017, 10, 382. [CrossRef] [PubMed]

8. Suh, B.C.; Hille, B. Regulation of ion channels by phosphatidylinositol 4,5-bisphosphate. Curr. Opin. Neurobiol. 2005, 15, 370-378. [CrossRef]

9. Di Paolo, G.; De Camilli, P. Phosphoinositides in cell regulation and membrane dynamics. Nature 2006, 443, 651-657. [CrossRef]

10. Rebecchi, M.J.; Pentyala, S.N. Structure, function, and control of phosphoinositide-specific phospholipase C. Physiol. Rev. 2000, 80, 1291-1335. [CrossRef]

11. Fitzjohn, S.M.; Collingridge, G.L. Calcium stores and synaptic plasticity. Cell Calcium 2002, 32, $405-411$. [CrossRef] [PubMed]

12. West, A.E.; Chen, W.G.; Dalva, M.B.; Dolmetsch, R.E.; Kornhauser, J.M.; Shaywitz, A.J.; Takasu, M.A.; Tao, X.; Greenberg, M.E. Calcium regulation of neuronal gene expression. Proc. Natl. Acad. Sci. USA 2001, 98, 11024-11031. [CrossRef] [PubMed]

13. Trovò, L.; Ahmed, T.; Callaerts-Vegh, Z.; Buzzi, A.; Bagni, C.; Chuah, M.; Vandendriessche, T.; D’Hooge, R.; Balschun, D.; Dotti, C.G. Low hippocampal PI(4,5) $\mathrm{P}_{2}$ contributes to reduced cognition in old mice as a result of loss of MARCKS. Nat. Neurosci. 2013, 16, 449-455. [CrossRef] [PubMed]

14. Landman, N.; Jeong, S.Y.; Shin, S.Y.; Voronov, S.V.; Serban, G.; Kang, M.S.; Park, M.K.; Di Paolo, G.; Chung, S.; Kim, T.-W. Presenilin mutations linked to familial Alzheimer's disease cause an imbalance in phosphatidylinositol 4,5-bisphosphate metabolism. Proc. Natl. Acad. Sci. USA 2006, 103, 9524-19529. [CrossRef]

15. Chun, Y.S.; Shin, S.; Kim, Y.; Cho, H.; Park, M.K.; Kim, T.-W.; Voronov, S.V.; Di Paolo, G.; Suh, B.C.; Chung, S. Cholesterol modulates ion channels via down-regulation of phosphatidylinositol 4,5-bisphosphate. J. Neurochem. 2010, 112, 1286-1294. [CrossRef]

16. Chun, Y.S.; Oh, H.G.; Park, M.K.; Cho, H.; Chung, S. Cholesterol regulates HERG K+ channel activation by increasing phospholipase C $\beta 1$ expression. Channels 2013, 7, 1-13. [CrossRef]

17. Chun, Y.S.; Oh, H.G.; Park, M.K.; Kim, T.-W.; Chung, S. Increasing membrane cholesterol level increases the amyloidogenic peptide by enhancing the expression of phospholipase C. J. Neurodegener. Dis. 2013, 2013, 407903. [CrossRef]

18. Lu, J.; Wu, D.M.; Zheng, Z.H.; Zheng, Y.L.; Hu, B.; Zhang, Z.F. Troxerutin protects against high cholesterol-induced cognitive deficits in mice. Brain 2011, 134, 783-797. [CrossRef] 
19. Ullrich, C.; Pirchl, M.; Humpel, C. Hypercholesterolemia in rats impairs the cholinergic system and leads to memory deficits. Mol. Cell. Neurosci. 2010, 45, 408-417. [CrossRef]

20. George, A.J.; Holsinger, R.M.; McLean, C.A.; Laughton, K.M.; Beyreuther, K.; Evin, G.; Masters, C.L.; Li, Q.X. APP Intracellular Domain Is Increased and Soluble Abeta is Reduced with Diet-Induced Hypercholesterolemia in a Transgenic Mouse Model of Alzheimer Disease. Neurobiol. Dis. 2004, 16, 124-132. [CrossRef]

21. Refolo, L.M.; Malester, B.; LaFrancois, J.; Bryant-Thomas, T.; Wang, R.; Tint, G.S.; Sambamurti, K.; Duff, K.; Pappolla, M.A. Hypercholesterolemia accelerates the Alzheimer's amyloid pathology in a transgenic mouse model. Neurobiol. Dis. 2000, 7, 321-331. [CrossRef] [PubMed]

22. Segatto, M.; Trapani, L.; Marino, M.; Pallottini, V. Age- and sex-related differences in extrahepatic low-density lipoprotein receptor. J. Cell. Physiol. 2011, 226, 2610-2616. [CrossRef] [PubMed]

23. Segatto, M.; Di Giovanni, A.; Marino, M.; Pallottini, V. Analysis of the Protein Network of Cholesterol Homeostasis in Different Brain Regions: An Age and Sex Dependent Perspective. J. Cell. Physiol. 2013, 228, 1561-1567. [CrossRef]

24. Marounek, M.; Volek, Z.; Skřivanová, E.; Czauderna, M. Gender-based differences in the effect of dietary cholesterol in rats. Cent. Eur. J. Biol. 2012, 7, 980-986. [CrossRef]

25. McLaughlin, S.; Wang, J.; Gambhir, A.; Murray, D. PIP(2) and proteins: Interactions, organization, and information flow. Annu. Rev. Biophys. Biomol. Struct. 2002, 31, 151-175. [CrossRef]

26. Janmey, P.A.; Lindberg, U. Cytoskeletal regulation: Rich in lipids. Nat. Rev. Mol. Cell Biol. 2004, 5, 658-666. [CrossRef] [PubMed]

27. Bodin, S.; Welch, M.D. Plasma membrane organization is essential for balancing competing pseudopod- and uropod-promoting signals during neutrophil polarization and migration. Mol. Biol. Cell 2005, 16, 5773-5783. [CrossRef]

28. Sánchez-Madrid, F.; Serrador, J.M. Bringing up the rear: Defining the roles of the uropod. Nat. Rev. Mol. Cell Biol. 2009, 10, 353-359. [CrossRef]

29. Liu, Y.; Casey, L.; Pike, L.J. Compartmentalization of phosphatidylinositol 4,5-bisphosphate in low-density membrane domains in the absence of caveolin. Biochem. Biophys. Res. Commun. 1998, 245, 684-690. [CrossRef]

30. Johnson, C.M.; Chichili, G.R.; Rodgers, W. Compartmentalization of phosphatidylinositol 4,5-bisphosphate signaling evidenced using targeted phosphatases. J. Biol. Chem. 2008, 283, 29920-29928. [CrossRef]

31. Johnson, C.M.; Rodgers, W. Spatial segregation of phosphatidylinositol 4,5-bisphosphate (PIP2) signaling in immune cell functions. Immunol. Endocr. Metab. Agents Med. Chem. 2008, 8, 349-357. [CrossRef] [PubMed]

32. Taguchi, K.; Kumanogoh, H.; Nakamura, S.; Maekawa, S. Localization of phospholipase C $\beta 1$ on the detergent-resistant membrane microdomain prepared from the synaptic plasma membrane fraction of rat brain. J. Neurosci. Res. 2007, 85, 1364-1371. [CrossRef] [PubMed]

33. Koudinov, A.R.; Koudinova, N.V. Cholesterol homeostasis failure as a unifying cause of synaptic degeneration. J. Neurol. Sci. 2005, 229, 233-240. [CrossRef] [PubMed]

34. Hu, G.; Antikainen, R.; Jousilahti, P.; Kivipelto, M.; Tuomilehto, J. Total cholesterol and the risk of Parkinson disease. Neurology 2008, 70, 1972-1979. [CrossRef] [PubMed]

35. Roy, A.; Pahan, K. Prospects of statins in Parkinson disease. Neuroscientist 2011, 17, 244-255. [CrossRef]

36. Puglielli, L.; Tanzi, R.E.; Kovacs, D.M. Alzheimer's disease: The cholesterol connection. Nat. Neurosci. 2003, 6, 345-351. [CrossRef]

37. Notkola, I.L.; Sulkava, R.; Pekkanen, J.; Erkinjuntti, T.; Ehnholm, C.; Kivinen, P.; Tuomilehto, J.; Nissinen, A. Serum total cholesterol, apolipoprotein E epsilon 4 allele, and Alzheimer's disease. Neuroepidemiology 1998, 17, 14-20. [CrossRef]

38. Wolozin, B.; Kellman, W.; Ruosseau, P.; Celesia, G.G.; Siegel, G. Decreased prevalence of Alzheimer disease associated with 3-hydroxy-3-methyglutaryl coenzyme A reductase inhibitors. Arch. Neurol. 2000, 57, 1439-1443. [CrossRef]

39. Martins, I.J.; Berger, T.; Sharman, M.J.; Verdile, G.; Fuller, S.J.; Martins, R.N. Cholesterol metabolism and transport in the pathogenesis of Alzheimer's disease. J. Neurochem. 2009, 111, 1275-1308. [CrossRef] 
40. Mori, T.; Paris, D.; Town, T.; Rojiani, A.M.; Sparks, D.L.; Delledonne, A.; Crawford, F.; Abdullah, L.I.; Humphrey, J.A.; Dickson, D.W.; et al. Cholesterol accumulates in senile plaques of Alzheimer disease patients and in transgenic APP(SW) mice. J. Neuropathol. Exp. Neurol. 2001, 60, 778-785. [CrossRef]

41. Jick, H.; Zornberg, G.L.; Jick, S.S.; Seshadri, S.; Drachman, D.A. Statins and the risk of dementia. Lancet 2000, 356, 1627-1631. [CrossRef] 